\title{
Perencanaan Sistem Instalasi Plambing Air Bersih Apartemen Royal Paradise Bandung
}

\section{HERDIYANA ${ }^{1}$, PRIYADI WIRASAKTI ${ }^{2}$, LINA APRIYANTI SULISTIOWATI ${ }^{3}$}

\author{
${ }^{123} J u r u s a n$ Teknik Lingkungan, Fakultas Teknik Sipil dan Perencanaan, \\ ITENAS \\ Email : herdiyanaherdiyana@gmail.com
}

\begin{abstract}
ABSTRAK
Jumlah penduduk Kota Bandung yang diperkirakan akan mencapai 4,1 juta jiwa dengan laju pertumbuhan penduduk $0.8 \%$ pada tahun 2031 telah melampaui daya dukung Kota Bandung sekitar 3,1 juta jiwa sehingga hadirnya hunian vertikal seperti apartemen dapat menampung populasi penduduk. Kegiatan sanitasi dalam gedung harus ditunjang dengan pemenuhan akan kebutuhan air bersih bagi semua penghuni, maka dari itu dibutuhkan perencanaan sistem plambing air bersih . Metode yang menjadi acuan adalah SNI 7065-2005 untuk perhitungan kebutuhan air bersih dan SNI 8153-2015 untuk penentuan dimensi pipa air bersih. Hasil perhitungan jumlah populasi menunjukan 744 jiwa. Total kebutuhan air bersih : 146,6 $\mathrm{m}^{3} /$ hari, Kapasitas tangki bawah : 175,9 m³, kapasitas tangki atas : 26,1 $m^{3}$. Berdasarkan hasil perencanaan dimensi pipa horizontal air bersih berkisar antara rentang 15 - $32 \mathrm{~mm}$, dimensi pipa vertikal $40 \mathrm{~mm}$, pompa yang dipasang adalah pompa sentrifugal dengan daya : 3,9 kW. Pompa booster dipasang untuk membantu tekanan di lantai 8 karena tidak memenuhi tekanan standar. Pipa yang digunakan untuk distribusi air bersih adalah jenis pipa PPR (Polypropylene Random).
\end{abstract}

Kata kunci: Apartemen Royal Paradise, Air bersih, Diameter pipa. 


\begin{abstract}
Bandung population is predicted to be 4,1 million inhabitant with population growth 0,8\% at 3,1 million inhabitant, in order that presence of vertical housing as the apartment can accommodate inhabitant. Sanitation activities in the building must be supported with meet to need of clean water demand for the residents, it needs planning plumbing clean water system to meet the needs of clean water demand in the apartment residents. The referred methods are (SNI 7065-2005) for the calculation of clean water requirements and (SNI 8153-2015) for the determination of pipe dimensions. The result of population calculation : 744 residents and the amount of water requirement : 146,6 $\mathrm{m}^{3}$ / day, ground water tank capacity : $175.9 \mathrm{~m}^{3}$ and the roof tank : $26.1 \mathrm{~m}^{3}$. Based on planning obtained for horizontal dimensions of the water pipe is 15 - 32, $40 \mathrm{~mm}$ vertical pipe. The pump is a centrifugal pump has a power : $3.9 \mathrm{~kW}$. The booster pump is installed to increase the pressure on the 8th floor, which doesn't meet the standard of pressure. Pipes used for the distribution of clean water is type of PPR pipe (Polypropylene Random).
\end{abstract}

Keywords: Royal Paradise Apartments, clean water, pipe diameter. 


\section{PENDAHULUAN}

Perkembangan pembangunan hunian vertikal di Kota Bandung dari tahun ke tahun terus meningkat. Jumlah penduduk Kota Bandung yang diperkirakan akan mencapai 4,1 juta jiwa dengan laju pertumbuhan penduduk $0.8 \%$ pada tahun 2031 telah melampaui daya dukung Kota Bandung yang sekitar 3,1 juta jiwa (RTRW, 2011-2031). Hunian vertikal yang fungsi utama sebagai hunian, kini bertambah fungsi menjadi tempat perbelanjaan, sarana pendidikan dan perkantoran. Seiring dengan bertambahnya fungsi hunian vertikal, berbanding lurus dengan bertambahnya penghuni dan kebutuhan akan air bersih.

Sanitasi dalam gedung adalah suatu usaha untuk memberikan fasilitas di dalam gedung dalam menjamin keadaan rumah selalu sehat dan bersih. Usaha ini ditunjang oleh adanya penyediaan air bersih yang cukup. Air bersih yang disediakan harus memenuhi syarat secara kualitas dan kuantitas. Syarat secara kualitas adalah air bersih yang disediakan harus memenuhi persyaratan kualitas air minum. Syarat kuantitas adalah air bersih harus tersedia pada saat kebutuhan jam puncak pemakaian air dan menit puncak pemakaian air.

Perencanaan sistem plambing air bersih pada gedung, berguna untuk mencukupi kebutuhan air bersih saat waktu pemakaian jam puncak. Perencanaan instalasi penyediaan air bersih dilakukan dengan metode berdasarkan SNI 03-7065 tahun 2005 tentang tata cara perencanaan sistem plambing untuk menghitung kebutuhan air bersih. Sistem penampungan air bersih yang direncanakan adalah sistem tangki atap, pada sistem ini air yang telah ditampung dalam tangki bawah di distribusikan ke tangki atas. Metode yang digunakan adalah berdasarkan literatur (Noerbambang \& Morimura, 2005) tentang perencanaan ,pemelihaaran sistem plambing dalam gedung.

Maksud dan tujuan perencanaan adalah merencanakan sistem instalasi air bersih dengan sistem tangki atap. Perencanaan sistem plambing air bersih meliputi penentuan jumlah populasi dalam gedung, perhitungan kebutuhan air bersih, perhitungan kapasitas tangki bawah, tangki atas. penentuan dimensi pipa air bersih dan perhitungan tekanan di titik kritis.

\section{METODOLOGI}

Perencanaan sistem plambing pada apartemen Royal Paradise Bandung dilakukan dengan cara sebagai berikut :

\subsection{Persiapan}

Melakukan studi literatur mengenai teori-teori yang berhubungan dengan sistem plambing, dasar-dasar perencanaan sistem plambing, standar yang digunakan dalam perencanaan dan peraturan-peraturan yang terkait dalam perencanaan. Standar dan peraturan yang terkait perencanaan berguna sebagai acuan dan/atau pedoman dalam mendesain instalasi sistem plambing.

\subsection{Pengumpulan data}

Pengumpulan data terdiri dari data primer, data primer merupakan data yang diperoleh dari hasil observasi daerah perencanaan Apartmen Royal Paradise Bandung. Data sekunder merupakan data yang diperoleh dari penelitian tidak langsung, data sekunder pada umumnya meliputi catatan dan laporan. Data primer dan data sekunder meliputi : 
- Data Primer

Denah setiap gedung (gambar arsitek) berfungsi untuk menerangkan keadaan gedung seperti jumlah lantai, fungsi tiap lantai, luas tiap ruangan untuk menghitung jumlah populasi dan merencanakan jalur pipa yang direncanakan.

- Data Sekunder

Data sekunder pada perencanaan sistem instalasi plambing air bersih meliputi denah setiap lantai (gambar arsitek) dan standar nasional indonesia (SNI) yang mengatur sistem plambing air bersih, tersaji pada bab 2.3 Pengolahan Data.

\subsection{Pengolahan Data}

Pengolahan data adalah penyusunan data menjadi bentuk data yang lebih ilmiah. Perencanaan dilakukan dengan menghitung desain yang direncanakan dengan mengacu pada beberapa referensi berikut :

1. Perencanaan dan Pemeliharaan Sistem Plambing (Noerbambang \& Morimura, 2005)

2. Data Arsitek (Ernst Neufert, 2002)

3. Standar Nasional Indonesia 8135-2015 tentang Sistem Plambing pada bangunan gedung.

4. Standar Nasional Indonesia 03-7065 Tahun 2005 tentang Tata Cara Perencanaan Sistem Plambing.

5. Pompa dan Kompresor Pemilihan, Pemakaian dan Pemeliharaan (Ir. Sularso, 1987)

Pengolahan data meliputi :

- Perhitungan jumlah populasi penghuni

Penentuan jumlah penghuni merupakan jumlah orang ditentukan dalam menempati apartemen Royal Paradise Bandung. Penghuni gedung dihitung berdasarkan luasan setiap ruang sesuai fungsinya yang terdapat dalam gedung. Penghuni yang terhitung merupakan penghuni apartemen, karyawan dan pengunjung yang terdapat dalam gedung.

- Perhitungan kebutuhan air bersih

Kebutuhan air bersih dihitung berdasarkan jumlah populasi yang terdapat pada apartemen dan berdasarkan alat plambing yang digunakan. Mengetahui pemakaian air rata-rata per orang per hari maka akan diketahui jumlah kebutuhan air bersih dalam sehari. Untuk menghitung kebutuhan air bersih perorang perhari menggunakan rumus dibawah ini berdasarkan (Noerbambang \& Morimura, 2005) :

Kebutuhan Air (Liter/Hari) = Jumlah populasi x Standar pemakaian air bersih

\subsection{Perencanaan Teknis}

Perencanaan teknis adalah tahapan dalam perhitungan dan penentuan dimensi jalur pipa air bersih, agar desain dapat berfungsi dengan baik dan memenuhi persyaratan teknis sistem plambing.

Perencanaan teknis terbagi dalam beberapa tahapan sebagai berikut :

1. Perhitungan kapasitas tangki bawah, tangki atas dan daya pompa Untuk mencari kapasitas tangki bawah pertama perlu diketahui total kebutuhan air bersih dikalikan $20 \%$ safety factor. Untuk menghitung volume tangki bawah dilakukan dengan rumus (Noerbambang \& Morimura, 2005): 
VGT $\left(\mathrm{m}^{3}\right)=$ Total air bersih $\left(\mathrm{m}^{3} /\right.$ detik $) \times($ safety factor $(20 \%))$

Setelah mencari kapasitas tangki bawah, dilakukan perhitungan kapasitas tangki atas untuk melayani jam dan menit puncak menggunakan rumus (Noerbambang \& Morimura, 2005) :

$\boldsymbol{Q}_{r}=\frac{V G T}{\text { Jamkerja }} \quad \boldsymbol{Q}_{\boldsymbol{p}}=\frac{Q_{r}}{C_{1}} \quad \boldsymbol{Q}_{\text {maks }}=\frac{Q_{p}}{C_{2}}$

Keterangan :

- $\quad$ VGT = Volume ground water tank

- Qr = Debit rata-rata $\left(\mathrm{m}^{3} / \mathrm{jam}\right)$

- $\quad$ Qp $\quad$ Kebutuhan jam puncak

- $\quad$ Qmaks $=$ Kebutuhan menit puncak

Penentukan kapasitas tangki atas perlu dilakukan perhitungan dengan menggunakan rumus berdasarkan (Noerbambang \& Morimura, 2005) :

VE $=[Q p-Q m a k] \times T p+(Q p u \times T P U)$

Keterangan :

- $\quad \mathrm{VE} \quad=$ Kapasitas efektif tanki atas $\left(\mathrm{m}^{3}\right)$

- $\quad \mathrm{Qp} \quad=$ Kebutuhan jam puncak (Liter/menit)

- $\quad$ Qmaks = Kebutuhan menit puncak (Liter/menit)

- $\quad \mathrm{TP} \quad=$ Jangka waktu kebutuhan puncak (menit)

- $\quad \mathrm{Qpu}=$ Kapasitas pompa pengisi (Liter/menit)

- $\quad \mathrm{TPU}=$ Jangka waktu kerja pompa pengisi (menit)

Perhitungan daya pompa dan pompa booster menggunakan rumus berdasarkan (Sularso, 1987) :

Power $(P)=\frac{Q \times \rho \times g \times H}{\text { Efisiensi pompa }(70-80 \%)}$

Keterangan :

- $\mathrm{P} \quad=$ Daya pompa $(\mathrm{kW})$

- $\rho \quad=$ Massa jenis air $\left(1.000 \mathrm{~kg} / \mathrm{m}^{3}\right)$

- $\mathrm{g}=$ Percepatan gravitasi $\left(9,81\right.$ meter/detik $\left.{ }^{2}\right)$

- $\mathrm{Q} \quad=$ Debit total air $\left(\mathrm{m}^{3} /\right.$ detik)

2. Perhitungan tekanan di Titik Kritis

Langkah menghitung kehilangan tekanan dilakukan perhitungan dengan menggunakan rumus berdasarkan (Noerbambang \& Morimura, 2005) :
$\boldsymbol{H}_{\text {Total }}$
$=$
$\left(H_{\text {Elevasi }+} H_{\text {Loss }} H_{V+}\right.$ Tekananawal)

(6)

Keterangan :

- $\quad H_{\text {Total }}=$ Tekanan energi (bar)

- $\quad H_{\text {Elevasi }}=$ Perbedaan elevasi pipa (meter)

- $\quad H_{\text {Loss }}=$ Kerugian gesek pipa (meter)

- $H_{V}=$ Kecepatan aliran air (meter) 
3. Menentukan jalur perpipaan

Menentukan jalur pipa horizontal dan vertikal yang efektif dan efisien. Jalur pipa efektif dan efisien yang dimaksud adalah jalur perpipaan yang tidak mengganggu fungi ruang yang lain, tidak melintang lift dan dekat dengan shaft / pipe gallery.

4. Penentuan dimensi pipa

Perhitungan dimensi pipa bertujuan untuk menentukan diameter pipa yang sesuai dengan standar, sehingga dapat memenuhi parameter teknis.

Berikut adalah diagram alir langkah kerja perencanaan sistem instalasi air bersih:

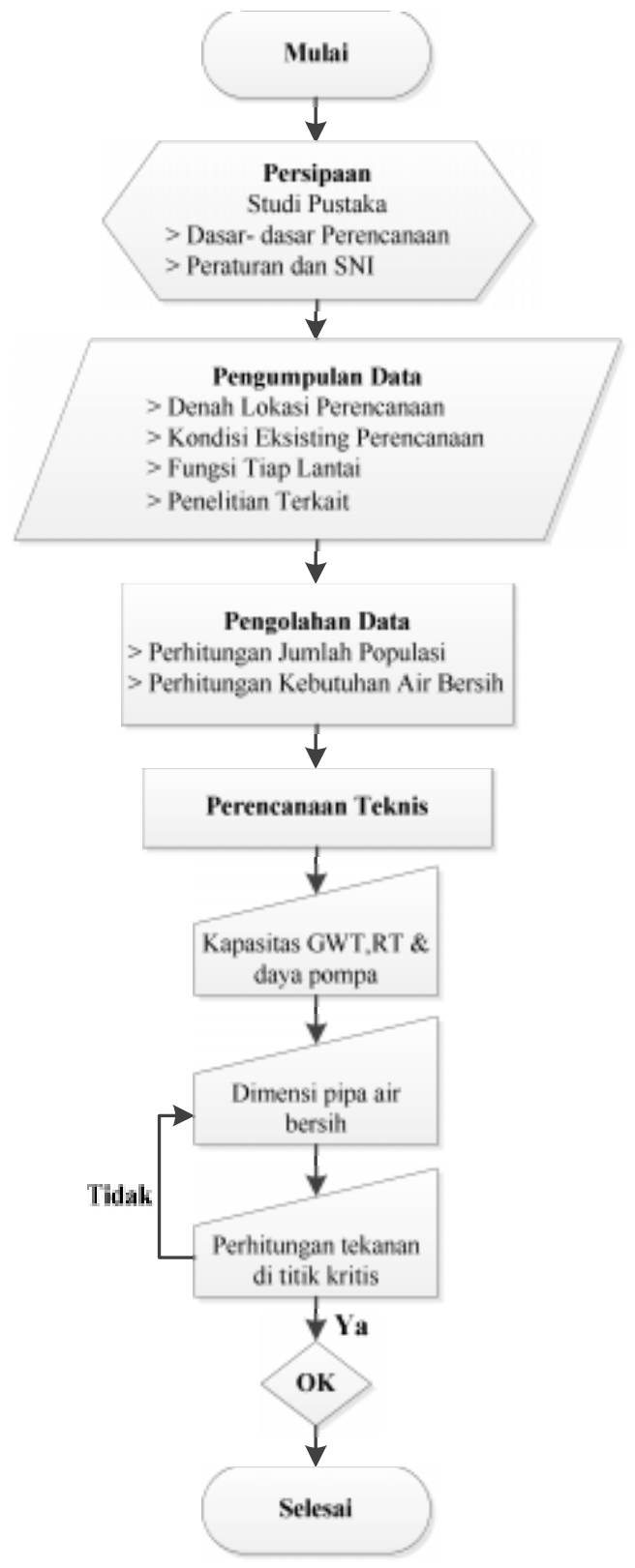

Gambar 1 Diagram Alir Langkah Kerja Perencanaan

[Reka Lingkungan] - 6 


\section{ISI}

Apartemen Royal Paradise Bandung adalah bangunan vertikal bertingkat yang berfungsi sebagai hunian sewa dan kepemlikan penuh. Apartemen ini memiliki luas lahan $3.633 \mathrm{~m}^{2}$ dan luas bangunan $1.695 \mathrm{~m}^{2}$. Apartemen Royal Paradise Bandung terdiri dari 13 lantai yang terdiri dari 3 lantai basement, 1 lantai dasar, 1 lantai bawah sebagai lobby, 7 lantai kamar apartemen dan 1 lantai atap. Lokasi perencanaan terletak di Jalan Gegerkalong Hilir No. 103-105 Setiabudi, kota Bandung, Jawa Barat.

\subsection{Perhitungan Populasi Apartemen}

Populasi apartemen menyatakan banyaknya jumlah penghuni, pengunjung dan karyawan yang menempati didalam apartemen. Luas ruangan dan fungsi ruangan merupakan data yang harus tersedia dalam melakukan perhitungan populasi apartemen. Tabel 1 menunjukan hasil perhitungan jumlah populasi apartemen Royal Paradise Bandung.

Tabel 1 Perhitungan Jumlah Populasi Apartemen Royal Paradise

\begin{tabular}{lccc}
\hline \multicolumn{1}{c}{ Lantai } & $\begin{array}{c}\text { Pengunjung } \\
\text { dan } \\
\text { Penghuni } \\
\text { (jiwa) }\end{array}$ & $\begin{array}{c}\text { Karyawan } \\
\text { (Jiwa) }\end{array}$ & $\begin{array}{c}\text { Jumlah } \\
\text { Populasi } \\
\text { (Jiwa) }\end{array}$ \\
\hline Lantai Basement 1 & - & 6 & 6 \\
\hline Lantai Basement 2 & - & 3 & 3 \\
\hline Lantai Basement 3 & - & 4 & 4 \\
\hline Lantai Dasar & - & 2 & 2 \\
\hline Lantai Bawah & 73 & 12 & 85 \\
\hline Lantai 2 & 92 & - & 92 \\
\hline Lantai 3 & 92 & - & 92 \\
\hline Lantai 4 & 92 & - & 92 \\
\hline Lantai 5 & 92 & - & 92 \\
\hline Lantai 6 & 92 & - & 92 \\
\hline Lantai 7 & 92 & - & 92 \\
\hline Lantai 8 & 92 & - & $\mathbf{7 4 4}$ \\
\hline
\end{tabular}

Sumber : Hasil Perhitungan, 2017

\subsection{Kebutuhan Air Bersih Berdasarkan Populasi}

Kebutuhan air bersih perhari dihitung dengan, mengkalikan jumlah orang dengan standar kebutuhan air bersih sesuai dengan fungsi ruangnya. Dari hasil perhitungan Kebutuhan Air Bersih didapat kebutuhan air bersih untuk karyawan yaitu $1.400 \mathrm{~L} / \mathrm{H}$, untuk pengunjung dan penghuni yaitu $120.770 \mathrm{~L} / \mathrm{H}$. Total kebutuhan air bersih untuk apartemen Royal Paradise Bandung adalah $146.604 \mathrm{~L} / \mathrm{H}$ atau $146,6 \mathrm{~m}^{3} / \mathrm{H}$. Sumber air utama untuk memenuhi kebutuhan air bersih apartemen Royal Paradise Bandung adalah PDAM Tirta Wening.

\subsection{Perhitungan Kapasitas Tangki Bawah (Ground Water Tank)}

Untuk menghitung kapasitas ground water tank pertama perlu diketahui total kebutuhan air bersih dikalikan $20 \%$ safety factor. Dari hasil perhitungan kapasitas tangki bawah didapat volume tangki bawah sebesar $175.92 \mathrm{~L}$ atau 175,92 $\mathrm{m}^{3}$ dengan dimensi panjang (p) 5,6 m, lebar (I) 5,6 m dan kedalaman (t) 3,6 m. 


\subsection{Perhitungan Kapasitas Tangki Atap (Roof Water Tank)}

Tangki atap berfungsi untuk mendistribusikan air bersih menuju semua lantai yang dilayani oleh alat plambing. Berdasarkan hasil perhitungan kapasitas tangki atap adalah $26,1 \mathrm{~m}^{3}$ dengan dimensi panjang (p) 2,9 m, lebar (I) 2,9 m dan kedalaman (t) $2 \mathrm{~m}$. Tangki yang direncanakan adalah 2 tangki tangka atap, 1 tangki sebagai sumber air utama dan 1 tangki sebagai cadangan. Tangki atap yang direncanakan adalah tangki atap panel fiber.

\subsection{Perhitungan Daya Pompa}

Daya pompa berfungsi untuk menaikan atau menghisap air dari tangka bawah menuju tangki atap melalui sistem perpipaan. Daya pompa yang dibutuhkan pada Apartemen Royal Paradise Bandung adalah 3.898,4 W atau 3,9 kW. Pompa yang digunakan adalah pompa jenis sentrifugal dengan merek Grundfos NF 30-36 T.

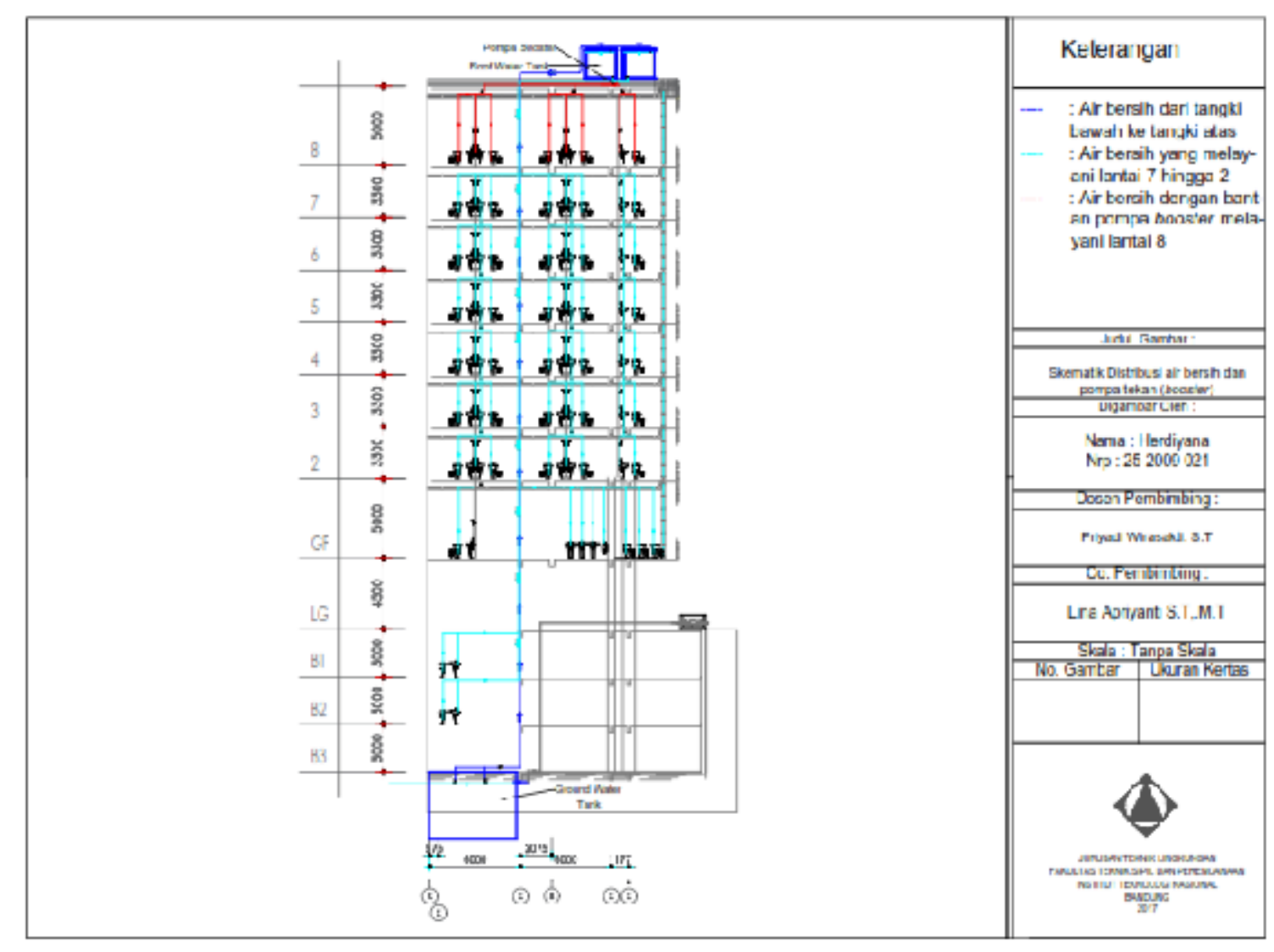

Gambar 2 Skematik Distribusi Air Bersih

Sumber : Hasil Perencanaan, 2017

Keterangan :

- Warna biru tua = air bersih yang didistribusikan dari tangki bawah ke tangki atap.

- $\quad$ Warna biru muda = air bersih yang melayani alat plambing dari lantai 7 hingga lantai basement 2.

- Warna merah = air bersih dengan bantuan pompa booster untuk melayani lantai 8. 


\subsection{Perhitungan Tekanan Di Titik Kritis}

Perhitungan tekanan pada apartemen Royal Paradise Bandung, dimulai dari lantai 8 karena pada lantai tersebut terdapat elevasi yang pendek dari tangki atap sehingga tekanan belum cukup untuk mendistribusikan air bersih ke alat plambing (shower) yang dilayani. Maka dari itu diperlukan memasang pompa booster agar dapat mendistribusikan air bersih ke titik kritis, agar memenuhi tekanan standar alat plambing shower 0,7 bar. Hasil perhitungan dan gambar tekanan di titik kritis untuk lebih jelasnya dapat dilihat pada Gambar $\mathbf{3}$ dan Tabel $\mathbf{2}$

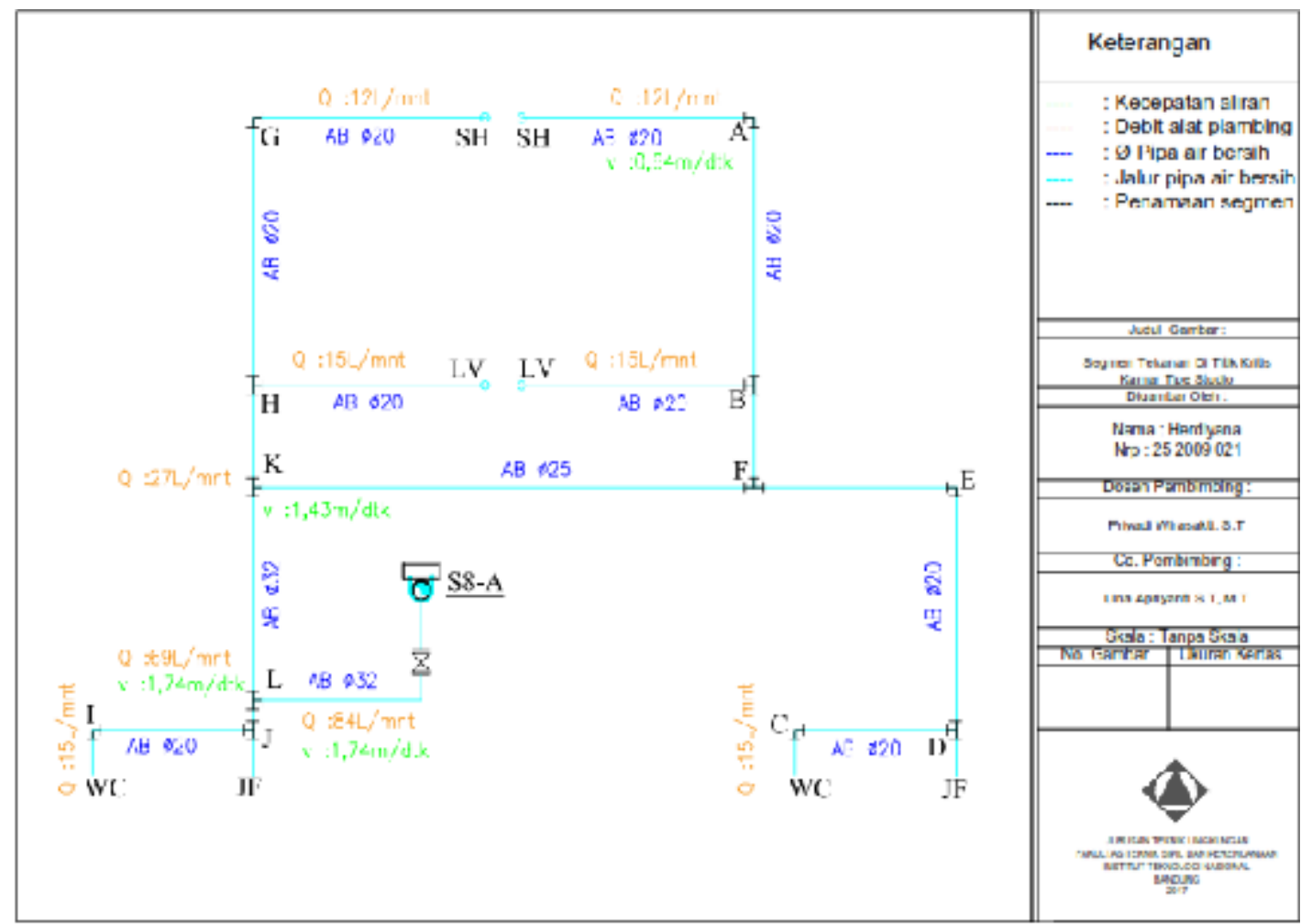

Gambar 3 Jalur Tekanan Di Titik Kritis Tipe Kamar Studio

Sumber : Hasil Perencanaan, 2017

Keterangan :

- Warna biru tua = diameter pipa air bersih.

- Warna biru muda = jalur pipa air air bersih.

- Warna orange $=$ debit setiap alat plambing .

- Warna hijau = kecepatan aliran.

- Warna hitam = penamaan segmen diameter air bersih.

Tabel 2 Perhitungan Tekanan Di titik Kritis

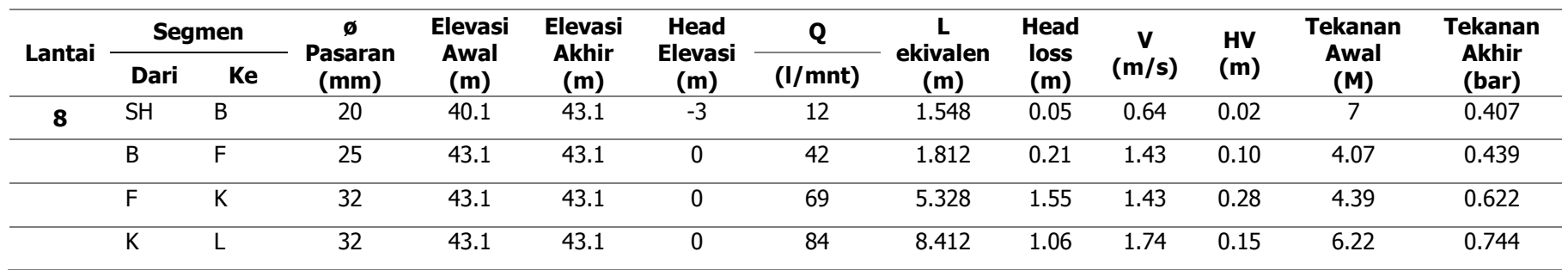




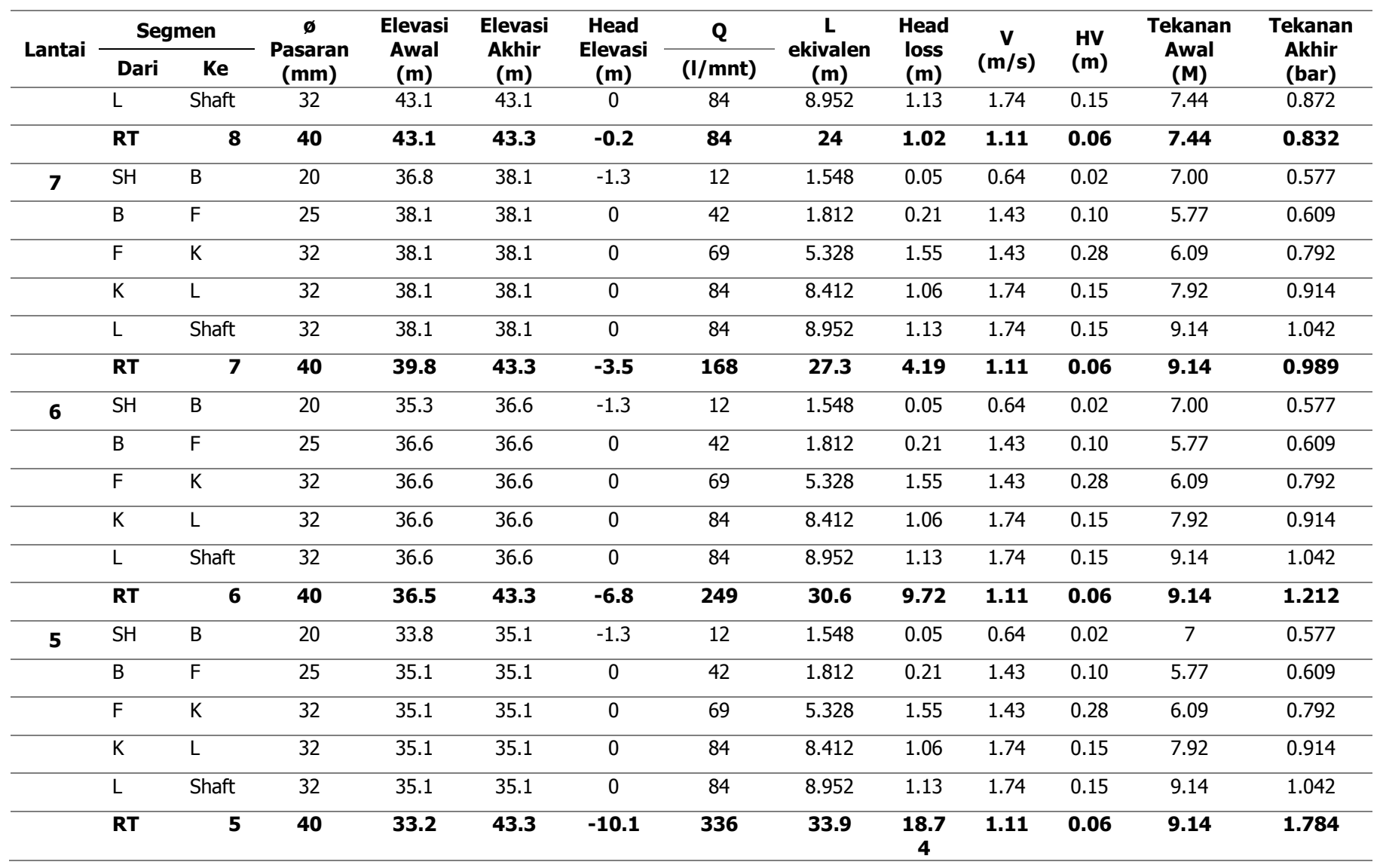

Sumber : Hasil Perhitungan, 2017

\subsection{Perhitungan Daya Pompa Booster}

Perencanaan sistem instalasi plambing air bersih dipasang pompa booster untuk menambah tekanan yang kurang menuju lantai 8 . Berdasarkan hasil perhitungan daya pompa booster apartemen Royal Paradise yang dapat adalah sebesar 229,4 W atau 0.2 kW.

\subsection{Penentuan Diameter Pipa Air Bersih}

Sebelum menentukan diameter pipa, terlebih dahulu mendesain jalur pipa air bersih agar mengetahui berapa alat plambing (FU) yang harus dilayani dan alat plambing apa saja yang digunakan. Nilai beban alat plambing (UBAP) diperlukan untuk menentukan diameter pipa air bersih. Untuk lebih jelasnya dapat dilihat contoh isometrik pada kamar tipe studio lantai 2-8: 


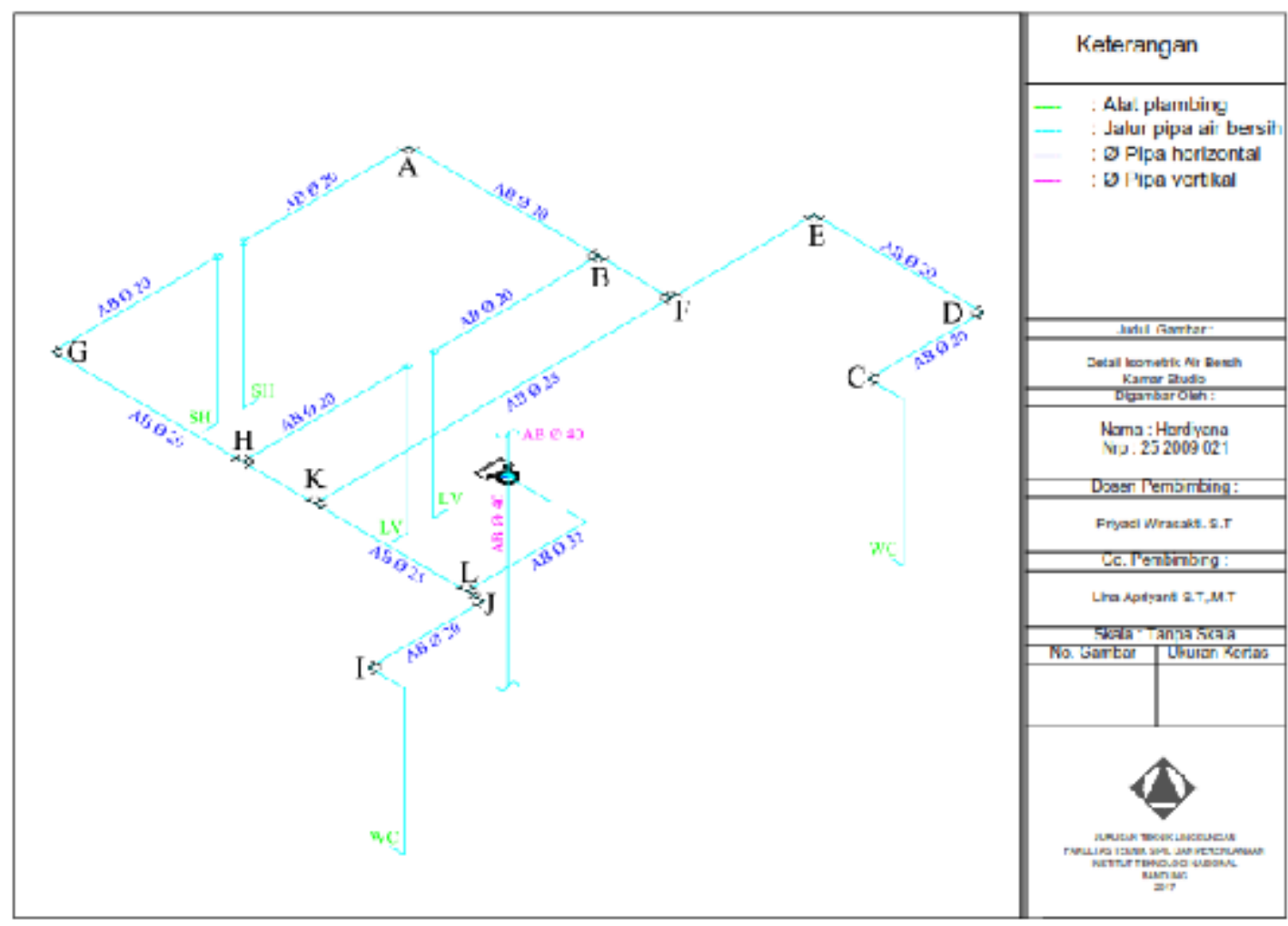

\section{Gambar 4 Isometrik Kamar Tipe Studio}

Sumber : Perencanaan, 2017

Keterangan :

- Warna biru tua = diameter pipa horizontalair bersih

- Warna biru muda = jalur pipa air air bersih.

- Warna hijau = penamaan alat plambing.

- Warna magenta = diameter pipa vertikal air bersih

- Warna hitam = penamaan segmen diameter air bersih.

Perhitungan diameter pipa dilakukan dengan menghitung akumulasi beban unit alat plambing yang dilayani. Setelah mendapatkan data akumulasi beban unit alat plambing (FU CUM), akan didapatkan diameter pipa air bersih. Untuk lebih jelasnya dapat dilihat pada Tabel 3 dan Tabel 4.

Tabel 3 Perhitungan Diameter Pipa Horizontal Lantai 8

\begin{tabular}{|c|c|c|c|c|c|c|c|c|}
\hline \multirow{2}{*}{$\begin{array}{l}\text { Fungsi } \\
\text { Ruang }\end{array}$} & \multicolumn{2}{|c|}{ Segmen } & \multirow{2}{*}{$\begin{array}{c}\text { Alat } \\
\text { Plambing }\end{array}$} & \multirow{2}{*}{$\begin{array}{l}\text { Jumlah } \\
\text { FU }\end{array}$} & \multirow{2}{*}{$\begin{array}{c}\text { FU } \\
\text { UBAP }\end{array}$} & \multirow[b]{2}{*}{ FU CUM } & \multirow{2}{*}{$\begin{array}{c}\varnothing \\
\text { Teoritis } \\
(\mathbf{m m})\end{array}$} & \multirow{2}{*}{$\begin{array}{c}\varnothing \\
\text { Pasaran } \\
(\mathbf{m m})\end{array}$} \\
\hline & Dari & $\mathrm{Ke}$ & & & & & & \\
\hline \multirow{10}{*}{$\begin{array}{l}\text { Tipe } \\
\text { Studio }\end{array}$} & $\mathrm{SH}$ & $A$ & Shower & 1 & 2 & 2 & 15 & 20 \\
\hline & LV & $B$ & Lavatory & 1 & 1 & 1 & 15 & 20 \\
\hline & WC & $\mathrm{C}$ & Water Closet & 1 & 2.5 & 2.5 & 15 & 20 \\
\hline & $\mathrm{D}$ & $E$ & & 2 & 2.5 & 5 & 15 & 20 \\
\hline & $E$ & $\mathrm{~F}$ & & 4 & & 5.5 & 15 & 20 \\
\hline & $\mathrm{SH}$ & $\mathrm{G}$ & Shower & 1 & 2 & 2 & 15 & 20 \\
\hline & LV & $\mathrm{H}$ & Lavatory & 1 & 1 & 1 & 15 & 20 \\
\hline & WC & I & Water Closet & 1 & 2.5 & 2.5 & 15 & 20 \\
\hline & G & $\mathrm{K}$ & & 2 & & 3 & 15 & 20 \\
\hline & J & $\mathrm{L}$ & & 2 & & 2.5 & 15 & 32 \\
\hline
\end{tabular}




\begin{tabular}{|c|c|c|c|c|c|c|c|c|}
\hline \multirow{4}{*}{$\begin{array}{l}\text { Fungsi } \\
\text { Ruang }\end{array}$} & \multicolumn{2}{|c|}{ Segmen } & \multirow{2}{*}{$\begin{array}{c}\text { Alat } \\
\text { Plambing }\end{array}$} & \multirow{2}{*}{$\begin{array}{c}\text { Jumlah } \\
\text { FU }\end{array}$} & \multirow{2}{*}{$\begin{array}{c}\text { FU } \\
\text { UBAP }\end{array}$} & \multirow[b]{2}{*}{ FU CUM } & \multirow{2}{*}{$\begin{array}{c}\varnothing \\
\text { Teoritis } \\
(\mathbf{m m})\end{array}$} & \multirow{2}{*}{$\begin{array}{c}\varnothing \\
\text { Pasaran } \\
(\mathbf{m m})\end{array}$} \\
\hline & Dari & $\mathrm{Ke}$ & & & & & & \\
\hline & K & $\mathrm{L}$ & & 6 & & 11 & 19.05 & 32 \\
\hline & $\mathrm{L}$ & Shaft & & 6 & & 11 & 19.05 & 40 \\
\hline
\end{tabular}

Sumber : Hasil Perhitungan, 2017 dan SNI 8153 - 2015

Tabel 4 Perhitungan Diameter Pipa Vertikal Lantai 8

\begin{tabular}{lccccc}
\hline \multicolumn{1}{c}{ Lantai } & Shaft & $\begin{array}{c}\text { Jumlah } \\
\text { FU }\end{array}$ & FU CUM & $\begin{array}{c}\boldsymbol{} \\
\text { Teoritis } \\
(\mathbf{m m})\end{array}$ & $\begin{array}{c}\boldsymbol{\emptyset} \\
\text { Pasaran } \\
(\mathbf{m m})\end{array}$ \\
\hline Lantai 8 & $\mathrm{S} 8-2$ & 6 & 11 & 38.1 & 40 \\
\hline Lantai 7 & $\mathrm{S} 7-2$ & 6 & 11 & 38.1 & 40 \\
\hline Lantai 6 & S6 - 2 & 6 & 11 & 38.1 & 40 \\
\hline Lantai 5 & S5 - 2 & 6 & 11 & 38.1 & 40 \\
\hline Lantai 4 & S4 - 2 & 6 & 11 & 38.1 & 40 \\
\hline Lantai 3 & S3 - 2 & 6 & 11 & 38.1 & 40 \\
\hline Lantai 2 & S2 - 2 & 6 & 11 & 38.1 & 40 \\
\hline Lantai Bawah & SBawah - 2 & 7 & 12.5 & 38.1 & 40 \\
\hline Lantai Dasar & SDasar - 2 & - & - & 38.1 & 40 \\
\hline Basement 1 & SBS3 - 2 & 3 & 5.5 & 38.1 & 40 \\
\hline Basement 2 & SBS2 - 2 & 3 & 5.5 & 38.1 & 40 \\
\hline Basement 3 & SBS1 - 2 & - & - & 38.1 & 40 \\
\hline & & $\mathbf{5 5}$ & $\mathbf{1 0 0 . 5}$ & $\mathbf{3 8 . 1}$ & $\mathbf{4 0}$ \\
\hline
\end{tabular}

Sumber : Hasil Perhitungan, 2017 dan SNI 8153 - 2015

\section{KESIMPULAN}

Sistem penyediaan air bersih yang direncanakan adalah menggunakan sistem tangki atap. Berdasarkan hasil perhitungan jumlah populasi apartemen adalah 27 jiwa untuk karyawan dan 717 jiwa untuk penghuni. Berdasarkan hasil perhitungan jumlah populasi, maka didapat jumlah total kebutuhan air bersih pada apartemen Royal Paradise Bandung sebesar 146,6 $\mathrm{m}^{3} / \mathrm{H}$. Kapasitas tangki bawah sebesar $175,9 \mathrm{~m}^{3}$, tangki atas sebesar $26,1 \mathrm{~m}^{3}$. Daya pompa yang direncanakan berdasarkan hasil perhitungan adalah 3,9 kW. Untuk memenuhi tekanan standar alat plambing shower 0,7 bar harus dipasang pompa tekan (booster) pada lantai 8. Daya pompa tekan (booster) yang didapat berdasarkan hasil perhitungan adalah sebesar 229,4 watt. Berdasarkan hasil perhitungan diameter pipa horizontal air bersih adalah 15 - 32 $\mathrm{mm}$ untuk alat plambing seperti lavatory, shower, water closet dan diameter pipa vertikal air bersih adalah $40 \mathrm{~mm}$.

\section{DAFTAR RUJUKAN}

Noerbambang, S. M., \& Morimura, T. (2005). Perancangan dan Pemeliharaan Sistem Plambing. Jakarta: Pt Prandya Paramita.

SNI 7065 - 2005. (2005). Tata Cara Perencanaan Sistem Plambing. Jakarta: BNS.

SNI 8153 - 2015. (2015). Sistem Plambing Pada Bangunan Gedung. Jakarta: BNS.

Sularso, H. T. (1987). Pompa dan Kompresor Pemilihan, Pemakaian dan Pemeliharaan. Jakarta: Pt Prandya Paramita. 